\title{
Technologies for producing syntactic carbon foams with specified operational properties
}

\author{
Engel Galimov ${ }^{1, *}$, Elmira Sharafutdinova ${ }^{1}$, and Nazira Galimova ${ }^{1}$ \\ ${ }^{1}$ Kazan National Research Technical University named after A.N. Tupolev-KAI, 420111, Kazan, \\ Russia
}

\begin{abstract}
Technologies for producing two classes of syntactic carbon foams of regular structure were developed: thermal insulating and heatconducting foams with specific physico-mechanical properties designed for operation under extreme conditions. The possibility of controlled development of porous structure in carbon foams upon their production by selecting the initial components in the form of binders, hollow particles (microspheres) and various additives (solvents, etc.), their optimal combination and ratio, as well as operating parameters of thermal processing. Phenol-formaldehyde resins, melamine and coal or oil pitches filled with hollow particles in the form of phenolic and carbon microspheres were used as starting components for the production of carbon foams. Technologies for producing carbon foams include the sequence of the following stages: preparation and mixing of the starting components, molding of samples, carbonization, graphitization, pyrocompaction and mechanical processing. Thermal insulation foams were obtained using two technologies. The first technology for producing foams involves using phenolic microspheres and a binder in the form of a phenol-formaldehyde resin of the novolac type. The second technology for producing foams through template carbonization involves the use of high porosity melamine with cellular structure as a binder, and hollow phenolic microspheres.
\end{abstract}

\section{Introduction}

Carbon foams (CF) fall into the class of modern composite materials with a high value of total porosity (60-70\% and more). A specific feature of the CF is the possibility of directional development of the porous structure during the technological process by selecting the initial components in the form of fillers, binders and various additives (solvents, etc.), their optimal combination and ratio, as well as operating parameters for heat treatment (carbonization, graphitization, pyrocompaction). In the process of producing the foams, it is possible to purposefully control the main parameters of the porous structure which have a significant influence on the change in thermophysical, physical and mechanical and other properties of materials [1-5].

\footnotetext{
*Corresponding author: engelgalimov@yandex.ru
} 
Among carbon foams, syntactic carbon foams (SCF) obtained using the hollow particles (microspheres) and binders in the form of polymers, pitches, and etc. as the initial components, take a special place in terms of their efficiency and perspectives of application. Such foams are characterized by the regularity of the structure, i.e., an elementary cell can be distinguished, and the structure of the whole material can be described by its multiple reiterations in space. The cells are macropores of approximately spherical shape and "windows" that provide the connection between the cells and the formation of a single open system of pores.

Research aimed at developing new technologies for producing foams with given thermophysical, mechanical and physical properties designed to operate in extreme conditions are relevant. Internationally, a number of industrial and laboratory technologies based on the carbonization of synthetic polymers filled with microspheres, foaming of carbon-containing substances followed by the carbonization, template carbonization of organic substances and polymers, compacting of expanded graphite, self-assembly of carbon nanoparticles, direct carbonization of natural raw materials, and etc. [1-4] are used for producing SCF.

The aim of the work is the development of technologies for producing heat-insulating and heat-conducting SCF with the given mechanical and physical properties. In order to achieve this goal, the following main problem was solved: to develop technology for producing two main classes of carbon foams: glass carbon-based heat-insulating carbon foams having at an apparent density of $0.1-1.0 \mathrm{~g} / \mathrm{cm}^{3}$, the ultimate compressive strength of at least 1.0 MPa and the thermal conductivity coefficient not more than $0.1-0.2 \mathrm{~W} / \mathrm{m} \cdot \mathrm{K}$; heatconducting syntactic carbon foams based on graphitizing including mesophase-forming materials which have at an apparent density $0.6 \mathrm{~g} / \mathrm{cm}^{3}$, the ultimate compressive strength of at least $1.0 \mathrm{MPa}$ and the thermal conductivity coefficient of not less than $150 \mathrm{~W} / \mathrm{m} \cdot \mathrm{K}$. It is necessary to select the initial components, determine their combinations and ratios, use specialized equipment, determine the optimal operating parameters of the technological process for producing SCF, and conduct research on their mechanical and physical, and thermophysical properties to do this.

\subsection{Initial components for producing foams}

Phenol-formaldehyde resins (PFR), melamine and pitches were used as a dispersion medium in for producing the foams. PFRs are products of phenol and formaldehyde polycondensation. Depending on the conditions of polycondensation, resol or novolac resins are formed; when they are heated the curing reaction with the formation of the polymer with a reticulate structure occurs. Melamine is a material based on hardened melamine formaldehyde resin (MFR). Pitches are remainders of the processing of coal-tar raw material or oil stock which are semi-solid amorphous substances with a softening temperature above the room temperature and characterized by a high carbon yield during heat treatment in an inert atmosphere (coking). Coal tar pitches are products of resin processing of hightemperature coking of black coal and are solids. Oil pitches are obtained from the remainders of the resin obtained in the process of oil pyrolysis. The anisotropic liquid crystal phase called the mesophase [1-3] is formed during the pyrolysis of isotropic coal tar or oil pitches in the temperature range of $300-500{ }^{\circ} \mathrm{C}$

Phenol formaldehyde (phenolic) and carbon microspheres were used as the dispersed phase of foams. Phenolic microspheres are produced by heat treatment of sprayed solutions or emulsions. Dilute solutions of resol PFRs containing up to $50 \mathrm{wt}$. \% of water and 6-9 wt. $\%$ of phenol are used to produce spherical-shaped particles. The production process includes the solvent evaporation and the heating of the sprayed monolithic particle, the expansion of vapors or gases inside the particle and the final curing of the microsphere. Microspheres are 
loose powder with the particle size of $10-300 \mu \mathrm{m}$ and bulk density of $100-1500 \mathrm{~kg} / \mathrm{m}^{3}$. The carbon microspheres are produced by carbonization of microspheres based on PFR at $900 \mathrm{C}$ in an inert gas environment. The microspheres have the diameter of 5-150 $\mu \mathrm{m}$, the wall thickness of 1-4 $\mu \mathrm{m}$ and bulk density of $130-140 \mathrm{~kg} / \mathrm{m}^{3}$ [1-3].

\section{Experimental part}

Heat insulating foams were produced using two technologies. The first technology for producing SCFs is based on the application of phenol microspheres using the "filler-binder" technology which includes the mixing of components, pressing of the mixture, heat treatment of the pressed workpieces, their pyrocompaction, and mechanical treatment to produce workpieces for testing. The PFR-based microspheres which are hollow spheres with a wall thickness of 1-2 $\mu \mathrm{m}$ were used as the filler. The average outer diameter of the microspheres was $34 \mu \mathrm{m}$. The novolac type PFRs were used as the binder. The second technology for producing the foams by templating carbonization involves the use of porous melamine of cellular structure (porosity 99.4\%) from which the samples of size from 10x10x20 mm to 20x30x30 mm were made. Since the yield of carbon residue from melamine is only 7-8 wt. $\%$ then at producing the foams its use as the template, i.e., the sacrificial polymer coated by material with the high yield of carbon residue. The samples were placed in a container filled with the solution of PFR in ethanol or acetone, the container was placed in a vacuum desiccator connected to the diaphragm pump (ILMVAC LVS-105T, residual pressure $8 \mathrm{~mm}$ $\mathrm{Hg}$ ). The container was evacuated before the start of gas evolution, the exposure for 3-5 minutes for the gas yield was made, then the vacuum level was raised by $5 \mathrm{~mm} \mathrm{Hg}$, bringing the residual pressure below the boiling point of the PFR solvent $(210 \mathrm{~mm} \mathrm{Hg}$ in case of acetone and $150 \mathrm{~mm} \mathrm{Hg}$ for ethanol), and then the exposure for 20 minutes was made. The PFR solutions in ethanol and acetone were prepared by heating the weighed portion of the resin in a solvent by mixing at $45^{\circ} \mathrm{C}$ and $65^{\circ} \mathrm{C}$ in the case of using, respectively, acetone and ethanol until complete dissolution with the exposure for 15 minutes at the final temperature.

Heat-conducting foams were produced using various technologies. The first technology is based on using the carbon microspheres and coal tar or oil pitch as the base components which are mixed at given ratios the solvent (toluene) is added to the mixture, heated in an oil bath, boiled using the backflow condenser at mixing after that the mixture is cooled, evaporated using the rotary evaporator to remove the toluene and dried under vacuum. The resulting mixture in the form of a granulated material is crushed and the "green" foam is molded by pressing the powder in the matrix under optimal conditions. Then, the workpiece is extracted and subjected to graphitization in a furnace at $2700{ }^{\circ} \mathrm{C}$ the graphitized workpiece is placed in a pyrocompaction furnace which is sealed, blown through with argon, the samples are heated and maintained at $800-1100{ }^{\circ} \mathrm{C}$, the pressure of 8-12 mm Hg within 20-120 hours.

The second technology for producing the foams by carbonization of pitches under pressure is based on the use of coal tar or oil pitch with the mesophase yield of at least $20 \mathrm{wt}$. $\%$. The mesophase microspheres produced by heat treatment of the initial pitch up to a temperature of mesophase formation $\left(400-500^{\circ} \mathrm{C}\right)$ followed by extraction of the soluble portion in toluene are added to the mixture to increase the thermal conductivity of the foams. The mesophase microspheres are added to increase the mesophase yield from pitch up to 40$50 \mathrm{wt}$. \%. The mixing of the components is carried out in a mixer at a temperature above the softening temperature of the pitch. Toluene is added to the mixture, mixed, boiled with backflow condenser for 60 minutes, and cooled, then, the solvent is extracted by distillation under vacuum using the rotary evaporator, drying is carried out under vacuum using a rotary evaporator at the temperature of $120^{\circ} \mathrm{C}$ and residual pressure of $10 \mathrm{~mm} \mathrm{Hg}$ for 60 minutes. After mixing the mixture is cooled and crushed in a vibrating mill, then, low-temperature carbonization of the "green" foam is conducted under pressure at $900{ }^{\circ} \mathrm{C}$. The obtained 
samples are placed in graphite crucibles with lids which are placed in an electrovacuum furnace, the working medium is pumped out to the residual pressure of less than $1 \mathrm{~mm} \mathrm{Hg}$. The furnace is heated for 8 hours up to $2100^{\circ} \mathrm{C}$ the samples are exposed for 2 hours then cooled and extracted. The final stages are graphitization at $2700{ }^{\circ} \mathrm{C}$ and pyrocompaction in the furnace which is sealed, blown through with argon, the samples are heated at $1100{ }^{\circ} \mathrm{C}$ and the pressure of 8-12 mm Hg within 20-120 hours.

The third technology for producing the foams by the carbonization of pitches under pressure is based on the introduction of the volatile substances into their composition at temperatures above $600{ }^{\circ} \mathrm{C}$. The initial components are the pitches and the mesophase microspheres produced by heat treatment of the pitches up to a temperature of mesophase formation $\left(400-500^{\circ} \mathrm{C}\right)$, the sodium chloride is used as the pore agent. The component mixing is carried out by joint grinding in a ball mill for 7 minutes. Then the molding powder is placed in a heated matrix and molded under pressure for 3 minutes. The resulting workpiece is extracted and carbonized. Next, samples of "green” foam are placed in a steel container, covered by the layer of broken graphite, a layer of tar pitch is poured on top, this is covered with a lid, placed in the furnace and heated at the rate of $2.5^{\circ} \mathrm{C} / \mathrm{min}$ up to $900^{\circ} \mathrm{C}$ for 120 minutes, after that the furnace is cooled. The resulting samples are placed in graphite crucibles with lids, and filling is poured. The crucibles are placed in an electrovacuum furnace the working medium is pumped out to the pressure of less than $1 \mathrm{~mm} \mathrm{Hg}$. The furnace is heated for 8 hours up to $2100^{\circ} \mathrm{C}$ the samples are exposed for 2 hours and then cooled. For graphitization, the samples are placed in graphite crucibles with lids, which are placed in a graphitization furnace with the temperature of $2700^{\circ} \mathrm{C}$ and the samples are exposed for 60 minutes. Then, the samples are loaded into a pyrocompaction furnace which is sealed, blown through with argon, heated and exposed at $1100{ }^{\circ} \mathrm{C}$ and the pressure of 8-12 $\mathrm{mm} \mathrm{Hg}$ within 20-120 hours. For the obtained samples, the apparent density, porosity, compressive strength, and thermal conductivity coefficient were determined using standard techniques [5-7].

The table 1 shows the comparison of the obtained experimental results (variants 1-5) with theoretical and published data (variants 6-12).

Table 1. Characteristics comparison of various types of syntactic carbon foams [8-11]

\begin{tabular}{|c|c|c|c|c|c|}
\hline No. & Variants of technology & $\begin{array}{c}\text { Density, } \\
\mathrm{g} / \mathrm{cm}^{3}\end{array}$ & $\begin{array}{c}\text { Porosity, } \\
\%\end{array}$ & $\begin{array}{c}\text { Strength, } \\
\mathrm{MPa}\end{array}$ & $\begin{array}{c}\text { thermal conductivity } \\
\text { coefficient, } \\
\mathrm{W} / \mathrm{m} \cdot \mathrm{K}\end{array}$ \\
\hline 1 & $\begin{array}{c}\text { Foams produced on the basis of } \\
\text { the carbon microspheres and } \\
\text { PFR }\end{array}$ & $0.07-0.80$ & $64-99$ & $5.2-23$ & $0.015-2.6$ \\
\hline 2 & $\begin{array}{c}\text { Foam produced by template } \\
\text { carbonization }\end{array}$ & $0.16-0.63$ & $71-93$ & $5.2-23$ & $0.9-3.1$ \\
\hline 3 & $\begin{array}{c}\text { Foams produced on the basis of } \\
\text { the carbon microspheres and } \\
\text { pitches }\end{array}$ & $0.25-0.67$ & $69.5-89$ & $9.6-19.2$ & $10-50$ \\
\hline 4 & $\begin{array}{c}\text { Foams produced by } \\
\text { carbonization under pressure }\end{array}$ & $0.88-1.08$ & $51-60$ & $26-33$ & $139.5-162.0$ \\
\hline 5 & $\begin{array}{c}\text { Foams produced using the } \\
\text { volatile pore agent }\end{array}$ & $0.21-0.39$ & $82-91$ & $5.4-12.6$ & $108-172$ \\
\hline 6 & $\begin{array}{c}\text { Foams produced on the basis of } \\
\text { carbon fiber P55 }\end{array}$ & 0.55 & 75 & 15 & 12 \\
\hline 7 & $\begin{array}{c}\text { Foams produced on the basis of } \\
\text { carbon fiber P120 }\end{array}$ & 0.55 & 75 & 25 & 60 \\
\hline 8 & Carbon foam ORNL & 0.60 & 73 & $20-25$ & 180 \\
\hline 9 & $\begin{array}{c}\text { Foam produced of pitch of } \\
\text { brand AR (2800 } \mathrm{C} \text { ) }\end{array}$ & 0.56 & 75 & 30 & 134 \\
\hline 10 & $\begin{array}{c}\text { Graphitized foam Conoco } \\
\text { (2800 }{ }^{\circ} \mathrm{C} \text { ) }\end{array}$ & 0.59 & 73 & 230 & 40 \\
\hline 11 & Copper foam & 2.25 & 75 & 68 & 15 \\
\hline 12 & Aluminum foam 6061 & 0.50 & 81 & 28 & \\
\hline
\end{tabular}


From the presented data it is clear that the foams produced using the technologies proposed in the paper surpass the majority of described analogues both on the basis of carbon and on the basis of polymers and metals per totality of the studied properties.

Based on the analysis of the conducted research, the possibility to use an integrated technology for producing heat-insulating foams with the thermal conductivity coefficient of less than $0.1-10 \mathrm{~W} / \mathrm{m} \cdot \mathrm{K}$ (SCF-1), highly heat- conductive foams with thermal conductivity coefficient from 50 to $160 \mathrm{~W} / \mathrm{m} \cdot \mathrm{K}$ (SCF-3), as well as foams with the intermediate value of thermal conductivity coefficient from 10 to $50 \mathrm{~W} / \mathrm{m} \cdot \mathrm{K}(\mathrm{SCF}-2)$ was established. The research results showed that the technology using carbon or phenolic microspheres and PFRs as a binder could be applied for the production of SCF-1. For the production of SCF-2, the technology based on pitches carbonization under pressure is the most optimal. Despite the significant difference of the early conversions (up to low-temperature carbonization) the same furnace equipment as for the previous approaches can be used for this one, which makes it possible to organize a flexible technology for the production of foams with various properties. Moreover, the same method of mixing (in a solvent, in a reactor with a stirrer, followed by evaporation using a rotary evaporator) is used for the production of foams with low and medium thermal conductivity coefficient. The processes similarity of subsequent heat treatment of the compositions provides the technical and economic advantages of the integrated technology as it allows significant reduction of the amount of the used processing equipment. The following equipment is necessary to organize a unified technological scheme for producing foams with various properties: a reactor with a stirrer and backflow condenser (SCF-1, SCF-2); mixing machine with Z-shaped blades (SCF-3); low-temperature furnace/drying furnace with heating up to the temperature of at least $150^{\circ} \mathrm{C}$ (SCF-1); ball mill (SCF-1 - SCF-3); hydraulic press (SCF-1, SCF-2); high-temperature autoclave $\left(550^{\circ} \mathrm{C} ; 15\right.$ $\mathrm{MPa}$ ) (SCF-3); kiln (up to the temperature of $1000^{\circ} \mathrm{C}$ ) (SCF-1 - SCF-3); electrovacuum furnace (up to the temperature of $2200^{\circ} \mathrm{C}$ ) (SCF-1 - SCF-3); graphitization furnace (up to the temperature of $3000^{\circ} \mathrm{C}$ ) (SCF-2, SCF-3); pyrocompaction reactor (SCF-1 - SCF-3).

The figure 1 shows the scheme for producing foams using integrated technology.

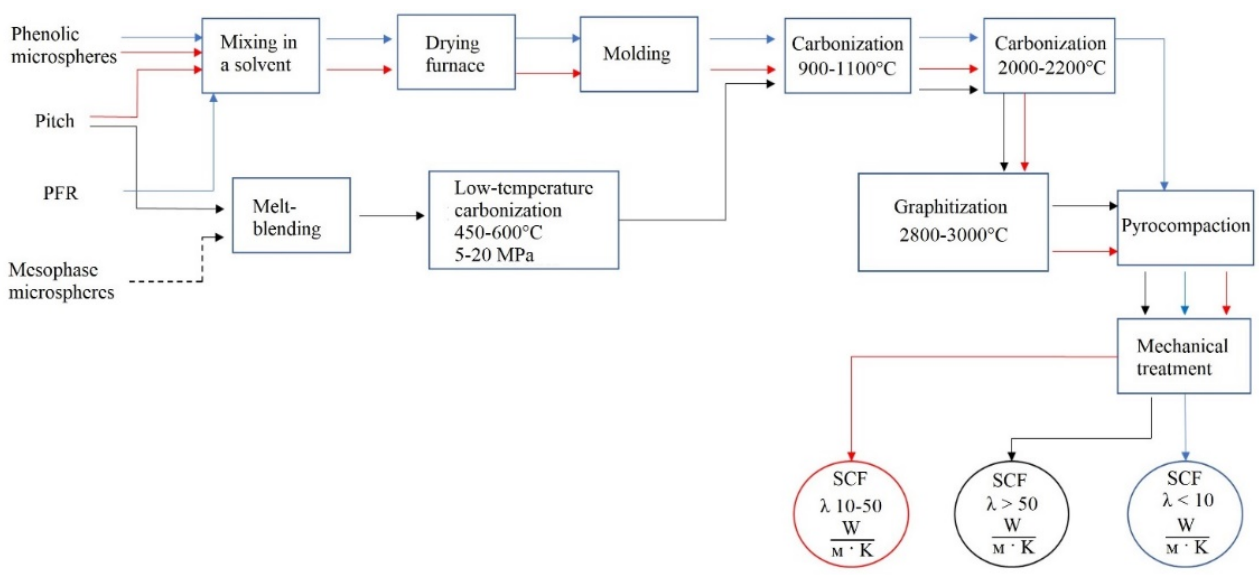

Fig. 1. Scheme of integrated technology for producing foams

\subsection{Practical significance}

SCFs can be used to control heat flows, create prospective current sources, as well as producing articles and elements of constructions in the defense technologies, aviation, and space; appropriateness and relevance of the technology for producing articles with given thermophysical properties for operating in extreme conditions based on the synthetic resins 
are shown; recommendations on the use of the research results in industrial enterprises are given.

\section{Conclusions}

Raw materials that provide a high degree of graphitization during heat treatment should be used to produce foams with high values of thermal conductivity coefficient. The necessary condition for this is the formation of a viscoplastic phase during carbonization an example of which is the mesophase as a liquid-crystalline state of a substance. This fact necessitates the use of mesophase-forming pitches (coal tar and oil) to produce articles with high values of thermal conductivity coefficient. In addition, it is possible to use additives of mesophase particles (microspheres) which can increase the average degree of material graphitization to increase the mechanical and physical properties and thermal conductivity coefficient of SCF. The regulation of the SCF macrostructure based on the graphitized materials, i.e., the creation of a regular system of spherical pores is possible through the use of additives of phenolic or carbon microspheres.

Synthetic polymeric binders (PFR, melamine formaldehyde resins) during carbonization form carbon characterized by the low thermal conductivity coefficient (not more than 10 $\mathrm{W} / \mathrm{m} \cdot \mathrm{K}$ ), so they are suitable for producing the heat-insulating SCFs. At the same time, the cellular polymers of honeycomb structure for producing the SCFs by the template synthesis method (melamine) are characterized by the low yield of carbon residue, which can lead to low mechanical and physical properties of the obtained articles. On the other hand, PFRs characterized by the high yields of carbon residue (up to $95 \mathrm{wt}$. \%) require the use of structuring additives and fillers (microspheres) to create materials with regular porous structure.

A unified integrated production technology that allows producing a wide range of ultrahigh-temperature carbon foams, including, those with a density of less than $0.6 \mathrm{~g} / \mathrm{cm}^{3}$ with the possibility of directional control of the thermal conductivity coefficient in the range from less than $0.1 \mathrm{~W} / \mathrm{m} \cdot \mathrm{K}$ to $160 \mathrm{~W} / \mathrm{m} \cdot \mathrm{K}$, was developed.

It was established that the processes parameters of producing the foams have a significant impact on the change in their properties and can be used as an effective factor in the directional control of the properties of the studied class of materials. From a comparison with the literature data, it is obvious that by the basic properties the obtained foams are on the level or significantly exceed the world analogs.

\section{References}

1. V.K. Tikhomirov, Foams. Theory and practice of their production and destruction, (Moscow, 1975)

2. F.A. Shutov, Syntactic polymer foams, Advances in Polymer Science, v. 73-74, pp. 63123, (1986)

3. M. Inagaki, J. Qiu, Q. Guo, Review Carbon foam: Preparation and application, Carbon, v. 87, pp. 128-15, (2015)

4. M.S. Anghelescu, Integrated Engineering Thermal and Mechanical Analysis of Carbon Foam, Ph.D. (2009)

5. Drew M., Engineered carbon foams are lightweight, high-temperature materials with tailorable strength and resistance to fire and chemicals, R.A.G. Spradling, URL: http://www.asminternational.org/documents/10192/1884784/amp16111p029.pdf/d156a ac6-369b-4a98-b4c2-0ea901e11fa1 
6. J. Klett, High Thermal Conductivity, Mesophase Pitch-Derived Carbon Foams, International Seminar on Advanced Applications for Carbon Materials, Jeju Island (2002)

7. Lei Shiwen, Guo Quangui, Shi Jingli, Liu Lang, Thermal-Insular Carbon Foam Prepared From Phenolic Resin, URL: http://acs.omnibooksonline.com/data/papers/2007_P106.pdf

8. P.S. David Stinton, Nidia C. Gallego, Brian Thompson, Qijun Yu, Tony Straatman, Carbon Foam Thermal Management Materials for Electronic Packaging, URL: http://www1.eere.energy.gov/vehiclesandfuels/pdfs/merit_review_2008/propulsion_ma terials/merit08_gallego.pdf

9. N.C. Gallego, J.W. Klett, Carbon Foams for Thermal Management, Carbon, v. 41, pp. 1461-1466 (2003)

10. L.A. Wamei, Review of Graphite Foam as Thermal Material, Project Report 200x MVK160 Heat and Mass Transport (Lund, Sweden, 2010)

11. L. Wamei, Yuan Jinliang, Bengt Sundén, Review on graphite foam as thermal material for heat exchangers, Energy End-Use Efficiency Issues (EEE). World Renewable Energy Congress. Linköping. Sweden (2011)

12. J. Klett, A. McMillan Heat exchangers for heavy vehicles utilizing high thermal conductivity graphite foams, SAE Technical Paper (2000)

13. Y.R. Lin, J.H. Du, W. Wu, L.C. Chow, W. Notardonato, Experimental study on heat transfer and pressure drop of recuperative heat exchangers using carbon foam, Journal of Heat Transfer, v. 132, (2010)

14. C. Duston, R. Watts, S. Seghi, B., Carney Strength enhancement and application development of carbon foam for thermal management systems, URL: www.dtic.mil/gettr-doc/pdf?AD=ADA457609

15. J. Klett, R. Ott, A. McMillan, Heat Exchangers for Heavy Vehicles Utilizing High Thermal Conductivity Graphite Foams (SAE Technical Paper, 2000)

16. S.A. Nada, W.G. Alshaer, Comprehensive parametric study of using carbon foam structures saturated with PCMs in thermal management of electronic systems, Energy Conversion and Management, v. 105, pp. 93-102 |(2015)

17. J.S. Coursey, R. Hongkoo, K. Jungho, P.J. Boudreaux, Graphite foam thermosyphon evaporator perfomance: parametric investigation of the effects of working fluid, liquid level, and chamber pressure, Proceedings of IMECE2002 ASME International Mechanical Engineering Congress \& Exposition (New Orleans, Louisiana, 2002)

18. B. Leyda, B. Ozmat, Phase-change thermal capacitors for ExoMars 2016 mission, 44th International Conference on Environmental Systems ICES (Tucson, Arizona, 2014)

19. K. Wierschke, Thermal characteristics of pitch based carbon foam and phase change materials, Thesis Air Force Institute of Technology, (AFIT/GSS/ENY, 2005)

20. A.D. Fedden Graphitized carbon foam with phase change material, Thesis Air Force Institute of Technology (AFIT/GA/ENY, 2006) 